\title{
The fertility of hypothyroid male mice
}

\author{
C. Chubb and L. Henry \\ Department of Cell Biology and Anatomy, University of Texas Southwestern Medical Center at \\ Dallas, Dallas, Texas 75235, U.S.A.
}

\begin{abstract}
Summary. Male mice homozygous for the hypothyroid gene mutation were compared with normal siblings to determine whether hypothyroidism induced infertility by impairing sexual behaviour. In addition, the fertility of the hypothyroid mice was examined. The experimental results provide unequivocal evidence that geneticallyinduced hypothyroidism in male mice does not impair sexual behaviour or cause infertility.
\end{abstract}

Keywords: hypothyroidism; male mice; sexual behaviour; genetically-defined mice

\section{Introduction}

Although thyroid hormones are known to modulate the activities of numerous biochemical processes (see DeGroot, 1979, for review), their influence on male reproduction has not been clarified. For example, hypothyroidism has been reported to either impair testicular function or to have no effect (see Gomes, 1970, for review).

Beamer et al. (1981) reported that hypothyroid male mice were infertile and that their infertility could be reversed by food supplemented with desiccated thyroid powder. Male mice homozygous for the hypothyroid gene mutation (hyt) are animal models of congenital hypothyroidism (Beamer et al., 1981; Beamer \& Cresswell, 1982). The primary action of the gene mutation is postulated to cause the thyroid to be unresponsive to thyroid-stimulating hormone (Beamer et al., 1981; Noguchi et al., 1986).

Our previous investigation of hypothyroid male mice (Chubb \& Nolan, 1985) revealed that their testicular function was not impaired. The goal of the present study was to determine whether the infertility was due to defective sexual behaviour. In addition, the fertility of hypothyroid male mice was assessed.

\section{Materials and Methods}

Animals. Male mice homozygous for the hypothyroid gene mutation $(h y t / h y t)$ and their normal male siblings $(+/-$; homozygous for the wild-type allele or unaffected heterozygote), 15 of each genotype, were purchased from The Jackson Laboratory (Bar Harbor, ME). The mice (strain C.RF-hyt, NI0 Fl4-N10 F15) were 6.5 \pm 0.3 (s.e.m.) weeks old when they arrived at our laboratory. Upon arrival, siblings were housed together (4/cage) in an environmentallycontrolled room $\left(23^{\circ} \mathrm{C}\right.$, lights on between 06:00 and 20:00 h). Food (Teklad 6\%; Teklad, Madison, WI) and water were available at all times. At 6-9 weeks of age, the mutant and control mice were assigned individual home cages and paired with proven-breeder BALB/c females (derived from our mouse colony) for $4-5$ weeks before the first sexual behaviour tests and during the intervals between the tests. Before organ collection, the mice were killed by cervical dislocation.

Sexual behaviour tests. Hypothyroid mice $(\mathrm{N}=12)$ and normal siblings $(\mathrm{N}=12)$ were selected randomly for the sexual behaviour tests. The mice were 12-14 and 23-29 weeks old when the tests began and ended, respectively. Sexual behaviour tests were performed according to our standardized protocol (Chubb, 1987; Chubb \& Henry, 1987) which is based on an earlier report by McGill (1962). Briefly, each mouse was tested 3-5 times at intervals of 2-3 weeks: females were removed from the cages 1 week before each test. The tests were performed in one designated test-room under fluorescent lighting and each pair of mice (mutant and control) was tested on the same day. For each test, a 
30-40-day-old BALB/c female, rendered oestrous by sequential injections of PMSG and hCG, was placed into the male's home cage and behavioural events were recorded. The tests were continued for 45 min unless the mouse ejaculated. A test was not scored if the male did not mount within $10 \mathrm{~min}$, the female was attacked repeatedly, or if the female did not exhibit a minimum receptivity as determined by a set of criteria defined by McGill (1962).

Fertility trials. Fertility was assessed when the mice were paired with proven breeder females. Each female was checked for vaginal plugs and litters 6 days per week. When the females were removed from the cage, they were earmarked, and checked for litters for 21 days. New proven breeders were added to the males' cages after the behaviour tests. During the fertility trials, each male was paired with $4.6 \pm 0.4$ different females for a total exposure time of $80 \pm 5$ days.

Miscellaneous methods. Thyroid function was evaluated by three methods: (1) determination of thyroid weight, (2) light microscopic examination of methacrylate-embedded thyroids (Chubb \& Henry, 1987), and (3) determination of plasma thyroxine concentrations by radioimmunoassays performed as described by Wilson et al. (1985) except that plasma instead of serum was assayed.

The behavioural event of ejaculation was confirmed by checking the female reproductive tract for spermatozoa by using a method similar to that described by Desjardins \& Lopez (1983). For this procedure, the female was killed within $5 \mathrm{~min}$ of an observed ejaculation and the vaginal plug, vagina, cervix and uterus were removed and homogenized. The number of spermatozoa per ejaculate was determined by examining the homogenates with a phase-contrast microscope.

Statistical analyses of the sexual behaviour tests were performed using the Wilcoxon Rank Sum Test. The significance of the difference between other means was assessed with the Student's $t$ tests. All results are expressed as the mean \pm s.e.m.

\section{Results}

\section{Sexual behaviour analyses}

There were no statistically significant differences between hypothyroid and control mice (Table 1). The mutant and control mice performed below expectations: only $46 \%$ and $44 \%$ of the behavioural tests for hypothyroid and control mice, respectively, were acceptable for analysis. The reasons for rejecting the tests were similar for both genotypes (see Table 1, footnote). Also, mice of both genotypes exhibited the same propensity for fighting with the females.

Table 1. Quantitative analyses of the sexual behaviour of hypothyroid mice (hyt/hyt) and their normal siblings $(+/-)$

\begin{tabular}{lcc}
\hline \multirow{2}{*}{\multicolumn{1}{c}{ Measurement }} & \multicolumn{2}{c}{ Genotype } \\
\cline { 2 - 3 } & Hypothyroid & Control \\
\hline Mount latency* (sec) & $258 \pm 55$ & $300 \pm 40$ \\
Intromission latency (sec) & $324 \pm 51$ & $499 \pm 99$ \\
$\quad$ Thrusts per intromission & $25 \pm 3$ & $37 \pm 4$ \\
$\quad$ Time per intromission & $25 \pm 2$ & $32 \pm 4$ \\
$\quad$ Intromissions before ejaculation & $11 \pm 3$ & $8 \pm 2$ \\
Ejaculation latency (sec) & $1162 \pm 178$ & $1017 \pm 114$ \\
Ejaculation duration (sec) & $13 \pm 1$ & $14 \pm 1$ \\
Total no. of accepted tests $\dagger$ & 21 & 21 \\
\hline
\end{tabular}

Values were derived by determining the mean of the tests for each mouse and calculating the mean \pm s.e.m. of the means for each genotype.

* Latencies refer to the time from the introduction of the female to the observation of the first mount, first intromission, or ejaculation.

$\uparrow$ Tests were not included for data analysis if more than one female was used ( 5 tests for hyt/hyt and 12 tests for $+1-$ ), no mounts occurred during the first $10 \mathrm{~min}(15$ tests for hyt $/$ hyt and 11 tests for $+/-)$, or females were unreceptive ( 5 tests for hyt/hyt and 4 tests for $+/-$ ). Three hyt/hyt mice and $2+1-$ mice did not have any test accepted for data analysis. 
A summary of all the sexual behaviour tests, acceptable and non-acceptable, provided more evidence that hypothyroidism did not affect sexual behaviour: hypothyroid mice intromitted and ejaculated in $61 \%$ and $59 \%$ of the tests, respectively, while control mice intromitted and ejaculated in $67 \%$ and $63 \%$ of the tests, respectively. Furthermore, hypothyroid and control mice ejaculated similar numbers of spermatozoa; $23 \pm 1 \times 10^{6}(\mathrm{~N}=24)$ and $28 \pm 2 \times 10^{6}(\mathrm{~N}=22)$, respectively.

\section{Fertility trials}

The fertility trials provided critical evidence that the hypothyroid mice were fertile: $92 \%$ of each genotype sired litters. The one hypothyroid mouse that failed to sire a litter also did not ejaculate during the sexual behaviour tests. The one control mouse that failed to sire a litter could not because his testes did not contain germ cells. One control mouse did not ejaculate during the sexual behaviour tests but did sire 3 litters. Hypothyroid and control mice sired a similar number of litters per mouse; $2.8 \pm 0.5$ and $4 \pm 0.5$, respectively. Also, the number of offspring per litter was not significantly different between hypothyroid $(6 \cdot 1 \pm 0 \cdot 3, \mathrm{~N}=32)$ and control $(5 \cdot 8 \pm 0 \cdot 3, \mathrm{~N}=37)$ mice.

However, the average age at which hypothyroid and control mice initiated their first pregnancy (determined as the male's age 3 weeks before the first litter) was significantly different $(13 \cdot 2 \pm 1 \cdot 4$ $(\mathrm{N}=14)$ and $10 \pm 0.7(\mathrm{~N}=14)$ weeks, respectively, $P<0.05)$. Although more than half of the males of each genotype inseminated the female during the first week of pairing, control mice were successful at 6-7 weeks of age while hypothyroid mice were not.

Body weights were monitored during the duration of the experiments. Initially, the hypothyroid mice weighed $60 \%$ of control weight. However, at 8-10 weeks of age, hypothyroid mouse weight increased from $60 \%$ to $80 \%$ of control values. At the conclusion of the study, the body weights of hypothyroid mice and control mice were within $10 \%$ of each other $(24 \pm 1(\mathrm{~N}=15)$ and $26 \pm 0.5$ $(\mathrm{N}=15) \mathrm{g}$, respectively) but significantly different $(P<0 \cdot 05)$.

\section{Reproductive organs}

Hypothyroidism did not affect circulating androgens since the weights of the androgendependent seminal vesicles were not significantly different between the two groups of mice $(242 \pm 14(\mathrm{~N}=15)$ and $267 \pm 8(\mathrm{~N}=14) \mathrm{mg}$, respectively). However, the absolute and relative weights of hypothyroid mouse testes were consistently larger $(P<0.001)$ than those of control weights $(5 \cdot 7(\mathrm{~N}=15)$ and $4 \cdot 3(\mathrm{~N}=14) \mathrm{mg} / \mathrm{g}$ body weight, respectively).

\section{Thyroid function}

All the measurements of thyroid function were performed at the completion of the studies when the mice were $24 \pm 1$ weeks old. The thyroids $(\mathrm{mg})$ of hypothyroid mice $(0 \cdot 8 \pm 0 \cdot 1, \mathrm{~N}=13)$ were significantly smaller $(P<0.001)$ than those of control mice $(1.6 \pm 0 \cdot 1, \mathrm{~N}=15)$. Radioimmunoassays of plasma thyroxine concentrations confirmed that the mutant mice were hypothyroid $(0.85 \pm 0.1(\mathrm{~N}=13) \mu \mathrm{g} / \mathrm{dl}$ compared with $2.4 \pm 0.1(\mathrm{~N}=13) \mu \mathrm{g} / \mathrm{dl}$ in controls $)$. Light microscopic examination revealed the presence of large follicles in thyroids of mice of both genotypes.

\section{Discussion}

The experimental results provide unquestionable evidence that the hypothyroid male mice were fertile. Furthermore, the hypothyroidism did not affect the sexual behaviour of the mutant mice. These results establish that genetically-induced hypothyroidism in mice does not cause male infertility as originally reported (Beamer et al., 1981). Although hypothyroid male mice were described as infertile by Beamer et al. (1981), the data supporting this conclusion were not included. 
Consequently, we cannot determine the basis for the profound difference between the experimental conclusions of our study and those of the original report. A change in the genetic background for the hypothyroid gene mutation could be involved.

Two earlier reports support our conclusion that hypothyroidism does not have a significant effect on the reproductive capacity of male mice homozygous for the hypothyroid gene mutation. Testicular steroidogenesis and sperm production are normal in hypothyroid mice (Chubb \& Nolan, 1985) and the plasma concentrations of LH, FSH, and testosterone are normal in hypothyroid mutant mice (Amador et al., 1986). These studies, together with the present findings, demonstrate that the hypothalamus-pituitary-testis axis, testicular function, sexual behaviour, and fertility are unaffected by the genetically-induced hypothyroidism.

The limited effects of hypothyroidism on reproduction in male mice are similar to those noted for man. The general consensus is that hypothyroidism is rarely a cause of infertility in men (White \& Nagler, 1982). One clinical study is frequently cited as evidence that hypothyroidism causes infertility in men: a 1962 report of 6 men that were either thyroidectomized or did not have palpable thyroids (De la Balze et al., 1962). These clinical results emphasize the different effects that severe and moderate hypothyroidism may have on male reproduction. This conclusion is illustrated by the recovery of the reproductive function of thyroidectomized rams when circulating thyroxine concentrations are restored to $30 \%$ of normal (Chandrasekhar et al., 1986).

In the present studies, the mice of each genotype did not perform well in the sexual behaviour tests. We concluded that the genetic background affected the poor performance since other strains of mice performed well under identical testing conditions (Chubb, 1987; Chubb \& Henry, 1987). The fact that testicular weights of hypothyroid mice were relatively larger than control values has been consistently observed in our investigations and has been reported for hypothyroid rats (Valle et al., 1985). The paucity of thyroid hormone receptors in testes (Müller \& Seitz, 1984) could cause testicular growth to be relatively unaffected by reductions in concentrations of circulating thyroid hormones. The sudden increase in body weight experienced by hypothyroid mice between 8 and 10 weeks of age but not by control mice did not correspond either with the pubertal increase in androgen secretion (McKinney \& Desjardins, 1973; Jean-Faucher et al., 1978) or endocrinological changes stimulated by the exposure to females. All of these observations remain unexplained.

In conclusion, the experimental data demonstrate that genetically-induced hypothyroidism does not induce infertility in male mice and does not deleteriously affect sexual behaviour of male mice.

We thank Dr Carol Wilson, Department of Internal Medicine, University of Texas Southwestern Medical Center at Dallas, for performing the thyroxine radioimmunoassays and for critical review of the manuscript. The reported studies were supported by Research Grant HD-15594 and Research Career Development Award HD-00725 (CC) from the National Institute of Child Health and Human Development, Bethesda, MD.

\section{References}

Amador, A.G., Parkening, T.A., Beamer, W.G., Bartke, A. \& Collins, T.J. (1986) Testicular LH receptors and circulating hormone levels in three mouse models of inherited diseases $(T f m / Y$, lit/lit and hyt/hyt). Endocr. exp. 20, 349-358.

Beamer, W.G. \& Cresswell, L.A. (1982) Defective thyroid ontogenesis in fetal hypothyroid (hyt/hyt) mice. Anat. Rec. 202, 387-393.

Beamer, W.G., Eicher, E.M., Maltais, L.J. \& Southard, J.L. (1981) Inherited primary hypothyroidism in mice. Science, N.Y. 212, 61-63.

Chandrasekhar, Y., D'Occhio, M.J. \& Setchell, B.P.
(1986) Reproductive hormone secretion and spermatogenic function in thyroidectomized rams receiving graded doses of exogenous thyroxine. J. Endocr. 111, 245-253.

Chubb, C. (1987) Sexual behavior and fertility of little mice. Biol. Reprod. 37, 564-569.

Chubb, C. \& Henry, L. (1987) Impotence induced by a single-gene mutation. Biol. Reprod. 36, 557-561.

Chubb, C. \& Nolan, C. (1985) Animal models of male infertility: mice bearing single-gene mutations that induce infertility. Endocrinology 117, 338-346.

DeGroot, L.J. (1979) Thyroid hormone action. In 
Endocrinology, Vol. 1, pp. 357-363. Eds L. J. DeGroot, G. F. Cahill, Jr, W. D. Odell, L. Martini, J. T. Potts, Jr, D. M. Nelson, E. Steinberger \& A. I. Winegrad. Grune and Stratton, New York.

De la Balze, R.A., Arrillaga, F., Mancini, R.E., Janches, M., Davidson, O.W. \& Gurtman, A.I. (1962) Male hypogonadism in hypothyroidism: a study of six cases. J. clin. Endocr. Metab. 22, 212-222.

Desjardins, C. \& Lopez, M.J. (1983) Environmental cues evoke differential responses in pituitary-testicular function in deer mice. Endocrinology 112, 1398-1406.

Gomes, W.R. (1970) Metabolic and regulatory hormones influencing testis function. In The Testis, Vol. 3, pp. 67-138. Eds A. D. Johnson, W. R. Gomes \& N. L. VanDemark. Academic Press, New York.

Jean-Faucher, C., Berger, M., De Turckheim, M., Veyssiere, G. \& Jean, C. (1978) Developmental patterns of plasma and testicular testosterone in mice from birth to adulthood. Acta endocr., Copenh. 89, $780-788$.

McGill, T.E. (1962) Sexual behavior in three inbred strains of mice. Behaviour 19, 341-350.

McKinney, T.D. \& Desjardins, C. (1973) Postnatal development of the testis, fighting behavior, and fertility in house mice. Biol. Reprod. 9, 279-294.

Müller, M.J. \& Seitz, H.J. (1984) Pleiotypic action of thyroid hormones at the target cell level. Biochem. Pharmacol. 33, 1579-1584.

Noguchi, T., Kudo, M., Sugisaki, T. \& Satoh, I. (1986) An immunocytochemical and electron microscopic study of the hyt mouse anterior pituitary gland. J. Endocr. $109,163-168$.

Valle, L.B.S., Oliveira-Filho, R.M., Romaldini, J.H. \& Lara, P.F. (1985) Pituitary-testicular axis abnormalities in immature male hypothyroid rats. J. Steroid Biochem. 23, 253-257.

White, R. \& Nagler, H.M. (1982) Endocrinologic causes of male infertility. In Aspects of Male Infertility, pp. 103-115. Ed. R. White. Williams and Wilkins, Baltimore.

Wilson, C.M., Griffin, J.E., Reynolds, R.C. \& Wilson, J.D. (1985) The interaction of androgen and thyroid hormones in the submandibular gland of the genetically hypothyroid (hyt/hyt) mouse. Endocrinology 116, 2568-2577.

Received 23 November 1987 